\title{
DO IDEAL AO MATERIAL Uma anatomia sócio-comportamental de um leilão holandês em Portugal
}

\section{Júlio Lobão}

Faculdade de Economia da Universidade do Porto, Porto, Portugal

Resumo Neste artigo levamos a cabo um estudo etnográfico de um leilão de pescado que tem lugar em Matosinhos (Portugal). A observação in situ do funcionamento do mercado aponta para a existência de uma comunidade de participantes coesa, marcada pela informalidade e pela aceitação tácita das regras constitutivas do leilão. As condições materiais de criação do mercado (organização do espaço, ecrãs, comandos de transmissão de ordens) revelam-se centrais no fortalecimento e na atenuação de dinâmicas de observação recíproca e de competição entre os agentes. Entendidas no seu conjunto, as contribuições deste artigo evidenciam a importância de se considerar as condições substanciais de criação de um mercado, por oposição a uma abordagem metodológica meramente formal.

Palavras-chave: sociologia económica, leilão holandês, sociologia da materialidade, economia substancial vs. economia formal.

\section{From ideal to material: a socio-behavioral anatomy of a Dutch auction in Portugal}

Abstract In this paper we carry out an ethnographic study at a fish auction that takes place in Matosinhos (Portugal). The in-situ observation of the functioning of the market suggests the existence of a cohesive community of participants, marked by informality and by the tacit acceptance of the constitutive rules of the auction. The material conditions of market creation (organization of the space, screens, remote control to transmit market orders) are central to the strengthening and weakening of the dynamics of mutual observation and competition among market participants. Taken together, the contributions of this paper highlight the importance of considering the substantive conditions of market creation, as opposed to a purely formal methodological approach.

Keywords: economic sociology, Dutch auction, sociology of materiality, substantial economy vs. formal economy.

De l'idéal au matériel: une anatomie socio-comportementale d'une vente aux enchères néerlandaise au Portugal

Résumé Dans cet article, nous menons une étude ethnographique lors d'une vente aux enchères de poisson à Matosinhos (Portugal). L'observation in situ du fonctionnement du marché suggère l'existence d'une communauté de participants cohésive, marquée par l'informalité et l'acceptation tacite des règles de comportement de la vente aux enchères. Les conditions matérielles de la création du marché (organisation de l'espace, écrans, télécommande pour transmettre les ordres) sont essentielles pour renforcer et atténuer les dynamiques d'observation mutuelle et de concurrence entre agents. Prises ensemble, les contributions de cet article soulignent l'importance de considérer les conditions substantielles de la création du marché, par opposition à une approche méthodologique purement formelle.

Mots-clés: sociologie économique, vente aux enchères néerlandaise, sociologie de la matérialité, économie substantielle vs. économie formelle.

Del ideal al material: una anatomía socio-conductual de una subasta holandesa en Portugal

Resumen En este artículo se realiza un estudio etnográfico a una subasta de pescado que tiene lugar en Matosinhos (Portugal). La observación in-situ del funcionamiento del mercado apunta a la existencia de una comunidad de participantes cohesiva, marcada por la informalidad y la aceptación tácita de las reglas constitutivas de la subasta. Las condiciones materiales de creación del mercado (organización del espacio, pantallas, comandos de transmisión de órdenes) se revelan centrales en el fortalecimiento y la atenuación de 
dinámicas de observación recíproca y de competencia entre los agentes. Entendidas en su conjunto, las contribuciones de este artículo ponen de manifiesto la importancia de considerar las condiciones sustanciales de creación de un mercado, en oposición a un enfoque metodológico meramente formal.

Palabras-clave: sociología económica, subasta holandesa, sociología de la materialidad, economía sustancial vs. economía formal.

In auctions, things are often not as they appear. Economic, psychological, and social concerns combine in a myriad of ways, both producing and reflecting the complex social context of the auction processes: the show itself

(Smith 1989: 130).

\section{Introdução}

Segundo a teoria económica neoclássica, um leilão pode ser encarado como um processo que permite o encontro de curvas de procura e de oferta, as quais refletem as preferências de um conjunto de agentes decidindo de forma autónoma e em função do seu interesse próprio. Neste contexto, diz-se que se gera, dessa forma, um preço correto.

No entanto, as investigações no campo da sociologia das finanças têm revelado algo de muito diferente (e.g., Smith, 1989; Glancy, 1990). Longe de ser um processo em que indivíduos calculistas e maximizadores da sua riqueza decidem de forma independente entre si, os leilões que ocorrem no mundo real são marcados por expectativas e estratégias de coligação, por tendências de imitação e de segredo, por invejas e emoções, por excitações e desejos. Em suma, trata-se dum mundo humano, profundamente humano, poderíamos dizer.

Neste artigo investigamos o funcionamento do leilão de pescado que ocorre regularmente na cidade de Matosinhos, em Portugal. O nosso objetivo é contribuir para o conhecimento de como se organizam os atores sociais neste cenário. Ao longo do nosso itinerário sublinhamos algumas das dissonâncias entre a instituição do leilão tal como é definida pela teoria económica neoclássica e a evidência recolhida. Para tal, seguimos o programa da sociologia das finanças (MacKenzie, 2006; Carruthers e Kim, 2011), contribuindo para esta corrente da literatura. O nosso estudo segue o método etnográfico, conferindo importância tanto às condições técnicas e organizacionais do mercado como aos indivíduos que nele operam. Ao longo dos últimos anos, a aplicação de estudos etnográficos tendo por objeto instituições económicas tem-se estabelecido nos estudos sociais, com uma variedade de abordagens que vão desde a imersão total nas instituições (e.g., Ho, 2009; Lépinay, 2011) a métodos mais variados que combinam histórias orais com observações in situ (e.g., Knorr Cetina e Bruegger, 2002; Zaloom, 2006).

Foram observadas na sua integralidade três sessões diárias de leilão de pescado durante o mês de janeiro de 2018. Cada sessão diária contemplou a licitação e venda de várias dezenas de lotes de pescado. A marcação das visitas obedeceu às 
restrições ditadas pela Docapesca. ${ }^{1}$ A primeira das visitas foi acompanhada, no seu início, por um funcionário da empresa que procedeu a uma apresentação sumária do sistema de leilão. Ao longo das sessões, foi possível ao investigador circular por toda a área do recinto onde decorreu a venda do pescado e interagir com os participantes no mercado de leilão. O investigador posicionou-se, na maior parte do tempo, no espaço dedicado ao público licitante. O interesse na obtenção de informação acerca das opiniões dos licitantes e dos funcionários da empresa gestora do leilão quanto ao funcionamento do mercado motivou algumas conversas informais com esses agentes. Estes momentos de interação ocorreram ao longo do período de funcionamento do mercado (e não em momentos predefinidos, antes ou depois de cada sessão de mercado). A intenção do investigador foi que a sua postura fosse suficientemente discreta para não se tornar num elemento perturbador do funcionamento do leilão. Julgamos que esse objetivo foi alcançado. Este artigo baseia-se, essencialmente, nas notas de campo do investigador relativas às visitas ao leilão, no seu diário pessoal, no registo fotográfico e de vídeo do evento, em documentação jornalística e institucional, bem como em conversas informais com os participantes no leilão.

Da nossa investigação emergiram três temas, correspondentes a tantas outras secções neste artigo, que passamos a expor. Assim, na secção seguinte apresentaremos a empresa gestora do leilão (Docapesca) bem como as principais características do leilão de pescado em Matosinhos. Entre essas características, que trazem implicações económicas e comportamentais à negociação, avultam o formato do leilão adotado (o chamado leilão holandês) e a velocidade de decréscimo dos preços apresentados aos potenciais licitadores. A terceira secção deste artigo será dedicada ao debate sobre os principais fatores de natureza comportamental, psicológica e social que resultam da participação no mercado de pescado em Matosinhos. A criação de um forte espírito de comunidade entre os participantes, bem como a tensão entre a observação dos concorrentes e a possibilidade de ser observado, são duas das principais questões abordadas nesta secção. A quarta secção abordará a questão da materialidade do mercado, ou seja, serão discutidas as implicações das escolhas tecnológicas efetuadas para a organização do leilão. Veremos aqui que a existência de artefactos, como ecrãs de informação e comandos de comunicação de licitações, traz implicações decisivas na forma como os atores sociais se organizam.

O itinerário adotado, conforme ficará mais evidente ao longo do artigo, inicia-se num domínio mais próximo do discurso económico, mas vai-se afastando progressivamente deste em direção a uma perspetiva mais sócio-comportamental, culminando com um olhar sobre a realidade material das trocas levadas a cabo.

1 É sabido que as observações etnográficas acerca das culturas de mercado são difíceis de realizar por se debaterem com numerosos obstáculos. No caso, as visitas ao leilão de pescado em Matosinhos estão sujeitas a autorização prévia da Docapesca (www.docapesca.pt), a empresa que gere o leilão. O registo fotográfico e em vídeo do funcionamento do leilão é, regra geral, interdito. No entanto, para efeitos da presente investigação, essa restrição foi levantada. Por este motivo, apresentamos aqui os nossos agradecimentos à Docapesca. 


\section{A Docapesca, o leilão holandês e o decréscimo dos preços}

A Docapesca, criada em 1956, é uma das maiores empresas europeias a atuar no sector das pescas. Explora em exclusividade um conjunto de 20 lotas e 50 outros pontos de venda de pescado em Portugal Continental.

O mercado de Matosinhos é um dos maiores em Portugal, sendo apenas ultrapassado em volume de pescado e em valor transacionado pelo de Sesimbra. O mercado tem crescido a um ritmo acelerado ao longo dos últimos anos. No simples período entre janeiro e junho de 2017 foram comercializadas mais de 4 mil toneladas de pescado na lota de Matosinhos, no valor de quase 7 milhões de euros (Docapesca, 2018). Em Matosinhos existem três diferentes mercados de peixe: a lota de cerco/sardinha que funciona diariamente a partir das 7 horas, a lota artesanal que se inicia às $16 \mathrm{~h} 30$ e a lota de arrasto a partir das 18 horas. É a lota que é responsável pelo pescado desde a sua pesagem até à entrega ao comprador (Docapesca, 1989). A nossa análise incidirá apenas sobre o funcionamento da lota de cerco/sardinha e da lota de arrasto.

O sistema de leilão mais divulgado a nível global é o chamado leilão ascendente (também designado leilão inglês), em que um leiloeiro divulga aos participantes um preço mínimo pelo bem leiloado, aceitando de seguida ofertas a preços sucessivamente superiores. O processo decorre até que a maior licitação permaneça sem ser superada durante um determinado período de tempo, findo o qual o bem é vendido ao preço correspondente à maior oferta. Embora o leilão inglês seja o mais comum, não é o sistema adotado nos leilões da Docapesca. Aqui, o leilão de pescado efetua-se por via eletrónica seguindo antes o chamado leilão descendente. No leilão descendente, também designado leilão holandês, o leiloeiro inicia o leilão estabelecendo um preço elevado e depois existe uma contagem decrescente até ser obtido o primeiro sinal de compra, que tem por finalidade suster a contagem num dado valor. Esse valor será então o preço produzido pelo leilão.

O leilão descendente remonta ao século XVI, quando era usado para vender flores na Holanda. Este formato de leilão é normalmente reconhecido como um mecanismo eficiente para vender rapidamente uma elevada quantidade de bens homogéneos, normalmente mercadorias como peixe, flores, tabaco e outros bens perecíveis (Adam et al., 2017).

É sabido que o comportamento dos agentes, bem como as suas preferências (em relação ao risco, por exemplo) variam de forma pronunciada com a forma como o leilão é organizado (Mirowski e Nik-Khab, 2007). Cada licitador está a concorrer contra a perceção da estrutura competitiva que tem perante si a cada momento. Assim, a escolha do formato do leilão e também dos seus parâmetros reveste-se de grande significado. Tendo sido escolhido para a Docapesca o leilão holandês, onde a primeira oferta é a vencedora, como deve o preço decrescer? De forma discreta, com reduções de preço periódicas, ou de forma contínua? No caso de alguns mercados de pescado como o Auckland Fish Market (Nova Zelândia) e o Sydney Fish Market (Austrália), os preços diminuem em intervalos de 10 segundos. Já no caso do mercado de Matosinhos, a descida ocorre de forma contínua ao longo do tempo. Outra escolha crucial é a da velocidade de redução do 
preço. A preferência por uma dada velocidade de redução de preço tem profundas implicações. De facto, a literatura sobre o tema tem estabelecido que o leilão holandês proporciona em média a mesma receita para o vendedor que o leilão inglês e mesmo outras formas de leilão, como o leilão com preços reservados (sealed-bid auction); na verdade, o leilão holandês pode até proporcionar receitas superiores às alternativas se a velocidade de diminuição do preço for reduzida (Lucking-Reiley, 1999; Katok e Kwasnica, 2008).

A literatura indica que a velocidade de diminuição dos preços é uma variável crítica na construção desses mercados (e.g., Adam et al., 2017). Não foi facultada informação acerca do algoritmo que regula a descida dos preços no caso do leilão da Docapesca. No entanto, da observação levada a cabo in situ e também da análise do registo em vídeo conclui-se que o percurso de descida dos preços (até ao preço de venda) foi semelhante em todos os leilões. A análise do registo em vídeo da evolução dos preços permitiu-nos estimar a velocidade de diminuição dos preços em função do nível de preços que vigora a cada momento. Essa estimativa, referente ao leilão de um lote específico e representativo da evolução dos preços nos leilões observados, encontra-se representada na figura 1.

Conforme se pode observar na figura 1 , o decréscimo dos preços no mercado de Matosinhos processa-se a uma velocidade muito elevada em níveis elevados de preços. Por exemplo, quando os preços se encontram acima dos 25 euros, observamos uma diminuição do preço em cerca de 8 euros por segundo. Isto significa que, por cada segundo que decorre, os licitadores podem adquirir o pescado a um preço 8 euros mais baixo. No entanto, para valores inferiores de preços a velocidade de variação destes é consideravelmente mais reduzida. Por exemplo, para preços em tornos dos 5 euros o decréscimo dos preços é de 1 euro por segundo; e para preços inferiores a 1 euro o decréscimo é inferior a 10 cêntimos por segundo.

É ainda mais relevante constatar que o decréscimo dos preços por segundo, em termos absolutos, é praticamente constante até o preço ter atingido os 25 euros; daí para baixo, o decréscimo dos preços é linear, ou seja, mantém-se numa relação aproximadamente constante entre a redução do preço por segundo e o preço de partida.

Da relação entre o preço de partida e o decréscimo dos preços é possível estabelecer a velocidade relativa, ou seja, a taxa de crescimento negativa dos preços. Os dados da figura indicam que a taxa de crescimento negativa dos preços é mais baixa nos valores mais elevados ( $12 \%$ a $17 \%$ por segundo entre os 60 euros e os $47 \mathrm{eu}-$ ros, aumentando para $21 \%$ a $26 \%$ na casa dos 30 euros), e acelera significativamente após se ter atingido o preço de 25 euros (alcançando taxas negativas de crescimento superiores a $30 \%)$.

Estes resultados suscitam várias notas. Em primeiro lugar, é necessário ter em atenção que a elevada velocidade de diminuição do preço para preços elevados não é muito relevante em termos económicos. A esmagadora maioria dos preços fixados por via do leilão de pescado em Portugal é inferior a 2 euros por quilo. Por exemplo, durante o ano de 2016, o preço médio do pescado vendido situou-se nos 1,28 euros por quilo, apesar de algumas espécies terem atingido preços médios bastante mais elevados, nalguns casos superiores a 4 euros por quilo (Docapesca, 2018). Em 


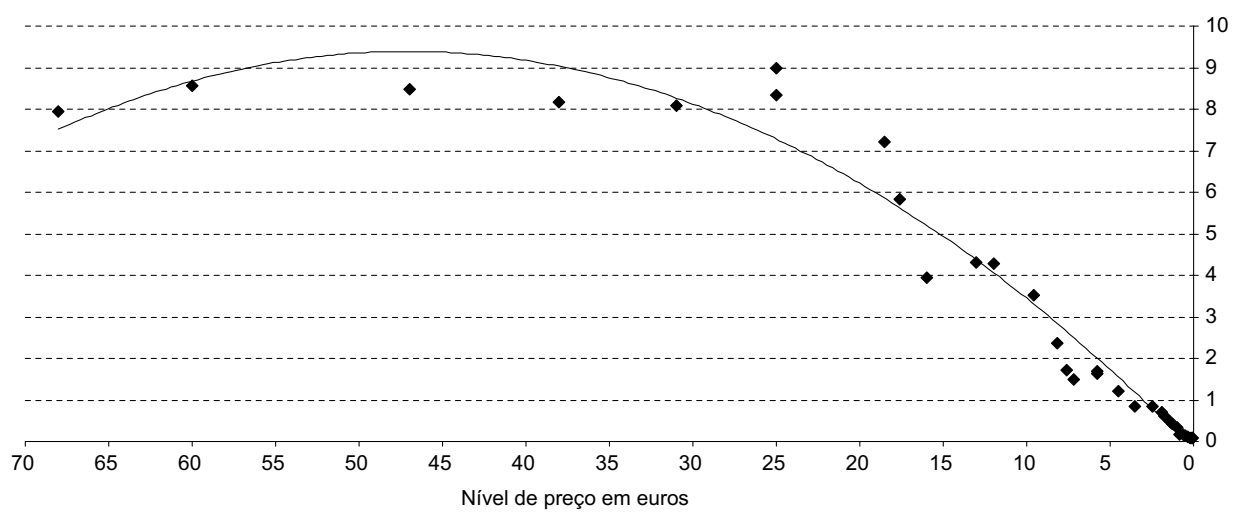

Figura 1 Estimativa da diminuição do preço (em euros por segundo) em função do nível de preço no leilão holandês da lota de Matosinhos, a partir da análise do registo em vídeo (com linha de tendência polinomial)

Fonte: elaboração própria, baseada no registo em vídeo do leilão, realizado pelo autor a partir de intervalos de variação de preços de amplitude variável.

segundo lugar, é interessante assinalar que a velocidade de diminuição dos preços para os níveis médio e médio/baixo, digamos, para preços inferiores a 1 euro por quilo, se encontra alinhada com a velocidade convencional adotada na maior parte dos estudos experimentais acerca do formato do leilão holandês reportados por Adam $e t$ al. (2017). Por último, seria interessante entender as motivações subjacentes à escolha de uma velocidade variável na diminuição dos preços do leilão. Como vimos, a estratégia na organização do leilão é a de baixar proporcionalmente mais devagar os preços altos, até à fronteira dos 25 euros, para em seguida abreviar comparativamente o leilão diminuindo os preços a um ritmo praticamente constante e relativamente acelerado. Não nos foi fornecida informação acerca da forma de remuneração da Docapesca, pelo que não nos é possível analisar de forma definitiva as motivações para a manipulação estratégica do tempo do leilão. No entanto, podemos assinalar que o padrão de evolução dos preços se revela consistente, por exemplo, com uma estrutura de remuneração do organizador do leilão baseada numa comissão proporcional ao valor da venda. Nestas condições, faria sentido, na perspetiva do organizador do leilão, procurar alongar o tempo de descida relativa dos preços mais elevados, dando mais tempo para os licitantes fecharem o negócio a esses preços, e acelerar a velocidade de descida para os preços mais baixos. A aceleração na velocidade de descida dos preços refletiria o facto de o valor da comissão compensar cada vez menos o custo de oportunidade do adiamento da abertura do leilão de um lote subsequente a um preço mais elevado, mais o custo reputacional para o organizador do leilão, se eventualmente não fosse capaz de leiloar todos os lotes oferecidos no período da sessão. ${ }^{2}$

2 Agradecemos a um dos avaliadores do artigo a chamada de atenção para o significado da relação potencial entre a velocidade de variação dos preços e as formas de remuneração do organizador do leilão. 
Mas a variação da velocidade de decréscimo dos preços não é a única escolha relevante na perspetiva da manipulação estratégica desse recurso escasso que é o tempo de duração de cada sessão de mercado. Como veremos com maior detalhe na quarta secção do presente artigo, no mercado de Matosinhos existem dois leilões a funcionar em simultâneo, o que permite que o tempo do leilão seja, na prática, duplicado com as óbvias consequências no aumento da quantidade de pescado que pode ser vendida por unidade de tempo.

Se o leilão holandês adotado no mercado de Matosinhos, na definição das suas variáveis críticas, como a velocidade de diminuição do preço, acarreta implicações económicas relevantes, as implicações comportamentais, psicológicas e sociais desse formato de leilão não se revestem de menor interesse. É a essa temática que dedicamos a nossa atenção na secção seguinte.

\section{Para além do económico: implicações comportamentais, psicológicas e sociais do leilão holandês}

\section{Construção de uma comunidade coesa}

A observação que fizemos da atuação dos licitadores no leilão da Docapesca em Matosinhos confirma a importância da componente social no comportamento desses agentes. O que presenciámos ao longo do leilão sugere que os participantes no evento constituem uma comunidade relativamente coesa, marcada por um elevado nível de proximidade e de conhecimento pessoal entre os participantes: os leiloeiros têm conversas (por vezes acaloradas) com os potenciais licitantes antes do início do leilão; no decurso do leilão é frequente os licitantes dirigirem-se aos leiloeiros ou aos assistentes do leilão pelo seu primeiro nome; da mesma forma, os leiloeiros não se coíbem de exprimir publicamente, durante o leilão, o seu estado de espírito do momento, interagindo com os licitantes, lançando piadas ou queixas irónicas e bem-humoradas. A perceção de que existe uma comunidade coesa em cada leilão é reforçada por outros elementos: em conversas informais com os assistentes do leilão (funcionários da empresa Docapesca) e com alguns licitantes pudemos saber que os participantes no mercado em cada dia da semana são quase sempre os mesmos; por exemplo, existem licitantes que comparecem ao leilão apenas à $2 .^{\mathrm{a}}$ feira e à $5 .^{\mathrm{a}}$ feira de cada semana, outros que comparecem apenas à $6 .^{\mathrm{a}}$ feira de cada semana e outros ainda que participam todos os dias no leilão. Este padrão sugere, portanto, que existe constância na comunidade presente em cada leilão e que, em cada dia, cada participante tende a encontrar frequentemente os mesmos licitadores. Tal contribui para reforçar os laços sociais existentes entre os seus elementos.

Neste contexto, a constatação de que existe um código de linguagem próprio dos participantes no leilão (licitantes, leiloeiro, assistentes do leilão) é também relevante por indicar existir um espírito de comunidade. A utilização de expressões por parte do leiloeiro como "a pescada está traçada", "a faneca é fraca", "pelo menos um linguado está batido" ou "este peixe está malhado", facilmente entendíveis pelos 
participantes habituais no leilão, mas relativamente estranhas para os leigos, sugere que existe uma fronteira entre estes dois grupos de indivíduos. Esta observação é reminiscente da constatação levada a cabo por outros estudos etnográficos em contexto de mercado, como o de Godechot (2001), que se debruça sobre os investidores na Bolsa de Paris. Godechot notou aí que a linguagem dos agentes de mercado para descrever a dinâmica dos produtos transacionados tendia a tornar-se altamente codificada e a desenvolver particularidades difíceis de entender pelos indivíduos exteriores à instituição.

Por último, as regras que regem o funcionamento dos leilões de pescado em Matosinhos também favorecem a criação dessa comunidade. O leilão de pescado é frequentado essencialmente por profissionais e a participação nos leilões está condicionada a um registo e credenciação caracterizado por procedimentos burocráticos diversos: segundo o regulamento interno de exploração das lotas, um indivíduo, para participar no leilão, tem que apresentar um mínimo de oito elementos, incluindo cartões de identificação e garantias bancárias. Isto significa que, ao contrário do que ocorre noutros leilões, um indivíduo recém-chegado e sem cumprir o devido procedimento de credenciação não pode participar no mercado. Esta barreira à entrada contribui, também ela, para criar um sentido de comunidade nos indivíduos que já fazem parte do grupo de compradores.

É ainda de referir que o sentimento de comunidade que encontramos não é exclusivo do leilão de pescado de Matosinhos. Por exemplo, o antropólogo Theodore Bestor (2004), na sua análise ao mercado de Tsukiji, o mercado de peixe de Tóquio, enfatiza a centralidade do social e da criação de uma comunidade (nakama, conforme é designada no caso japonês) no funcionamento do mercado. São os próprios participantes desse mercado que afirmam que a obtenção de lucro não constitui o aspeto mais importante da sua atividade. A criação de relações socialmente produtivas com os concorrentes e clientes, a comunicação interpessoal (não mediada por tecnologias como computadores e telefones) entre os elementos da comunidade e o sentimento lúdico na negociação, são diversos temas mencionados pelos participantes nesse mercado (Bestor, 2004).

A coesão da comunidade do leilão é pois um elemento chave para entender as preocupações dos participantes quanto à legitimidade no funcionamento do mercado. É de esperar que exista uma relação inversa entre a coesão do grupo e a necessidade de regras explícitas para garantir a legitimidade das transações (Smith, 1989). Quando o sentido de comunidade é forte, conforme é sugerido pelas nossas observações, as decisões ocorridas tendem a ser encaradas como um reflexo das avaliações dos participantes e a questão da legitimidade dessas decisões tende a não surgir de forma explícita; é antes assumida de forma tácita. Esta interpretaçãoé confirmada pela constatação de que no caso da lota de Matosinhos não se sente a necessidade de tornar explícitas as regras de funcionamento do leilão. Por exemplo, o leiloeiro não despende tempo a enunciar essas regras nem são disponibilizadas aos participantes cópias dos regulamentos. Seria de esperar assistir-se à comunicação mais ou menos formal das regras, se o sentido de comunidade fosse mais difuso. Para além disso, a aceitação da mudança de opinião de um licitador imediatamente após a compra de um item, porque este não é o que pensava ser ou 
porque se encontrava danificado (um evento por nós presenciado), é consistente com esse forte sentido de comunidade, em que as regras são implícitas e em que os participantes dispensam a necessidade de consulta dessas regras após cada procedimento menos habitual. ${ }^{3}$

\section{O papel da confiança}

A existência de um forte espírito de comunidade não afasta o sentido de competição entre os licitantes de um leilão. Este facto tem sido sublinhado na literatura: a existência de uma maior carga de sociabilidade entre os competidores (medida, por exemplo, através de uma maior densidade nas informações interpessoais entre os indivíduos) pode estimular a natureza competitiva no caso do leilão descendente (Rafaeli e Noy, 2005). Para além disso, a pressão do tempo - o preço desce de forma contínua no mercado de Matosinhos e, em geral, a venda de cada lote de pescado demora apenas alguns (poucos) minutos - estimula ainda mais a atenção dos licitadores e a propensão para competir (Giulioni e Bucciarelli, 2011). A nosso ver a asserção de Smith (1989: 117) ilustra, de forma incisiva, as implicações para a competição do forte sentido de comunidade existente no leilão de Matosinhos:

In exchange auctions and other auctions where there exists a cohesive community, the anxiety is linked to the awareness that while the members of the Exchange are united in certain respects, they are also in direct competition with each other. Trust is consequently always limited. Participants may be willing to take each other's word, but they would prefer it if the word was spoken publicly. It is such interpersonal uncertainty - as much as uncertainty in value, price, and allocation - that promotes and supports auctions.

O papel da confiança é essencial no funcionamento de qualquer mercado e, conforme se pode depreender da citação, o mercado de leilões não é exceção. Sem confiança entre os agentes, os custos de monitorização do cumprimento do acordado tornar-se-iam incomportáveis. No caso dos compradores, a desconfiança far-se-ia sentir, sobretudo acerca da qualidade do pescado. Dada a importância da confiança para o eficiente funcionamento do mercado, não é surpresa constatar a existência de mecanismos mais ou menos institucionalizados para lidar com a questão. Por exemplo, aos compradores nos leilões da Docapesca é facultada a possibilidade de inspecionar a qualidade do pescado in situ, antes de o leilão ter lugar. Todavia, mais importante é notar que a instituição de um espírito de comunidade, esse sentimento de pertença a um mesmo grupo, não pode deixar de ser considerado como o principal fator criador de confiança entre os seus membros. Só assim

3 A nossa constatação de que os indivíduos presentes no leilão constituem uma comunidade coesa revela-se consistente com a observação de que os elementos do grupo se mobilizam de forma solidária na defesa dos seus interesses. Foi isso que ocorreu recentemente quando um grupo de 500 pescadores encerrou a lota de Matosinhos em protesto contra o que alegam ser as práticas de fiscalização excessiva das autoridades (Público, 2018). 
pode ser entendido que, de acordo com o regulamento do leilão, caiba aos representantes dos armadores (uma das partes interessadas na transação) cuidar da classificação do pescado no que respeita à sua espécie, calibragem e grau de frescura.

Ao contrário do que ocorre no leilão inglês, no leilão de tipo holandês cada um dos potenciais licitantes participa num jogo marcado pela espera e pela expectativa, e não pela ação. O equilíbrio na atuação pode, no entanto, ser difícil de atingir: se a espera for demasiado curta, isso significa que o licitante vencedor vai adquirir o bem a um preço demasiado elevado; se a espera for demasiado longa, o participante interessado no bem arrisca ser ultrapassado por um rival. Assim, a visibilidade pública da rivalidade entre os licitantes no caso do leilão descendente não parece ser tão manifesta. No entanto, concluir daqui que não existe uma acesa rivalidade entre os participantes - com as consequentes implicações emocionais e sociais - é precipitado.

De facto, a natureza dinâmica do leilão holandês requer que os licitadores se reúnam num dado momento e num determinado espaço. E isso, por si só, tem implicações sociais. O leilão induz uma excitação emocional nos licitadores (Smith e Dickhaut, 2005; Hariharan et al., 2015), em particular quando é elevada a velocidade da diminuição do preço que todos os participantes observam; e isso traduz-se em menores preços finais (Hariharan et al., 2015; Adam et al., 2017). A manipulação da variável tempo é crucial: o tempo do leilão holandês é um tempo artificial e acelerado, associado à redução dos preços em vigor, em lugar do desenvolvimento das licitações no tempo real, algo típico do leilão inglês. Sendo artificial o tempo de vivência do leilão holandês, estão abertas as portas para a ocorrência de escolhas estratégicas e de iniciativas de manipulação dessa variável, conforme é fácil compreender.

Uma vez que o leilão holandês se faz pela espera e não pela competição direta entre licitações sucessivamente superiores, o papel da observação dos concorrentes é algo que deve ser ponderado. De acordo com a teoria neoclássica, a informação que um participante que decide de forma autónoma e calculista retira da observação dos seus concorrentes não deveria ser relevante. A constatação de que os preços continuam a diminuir deveria ser suficiente para perceber que não houve, até ao momento, quaisquer licitações. Apesar disso, e ao contrário desta perspetiva, o contexto de competição social que presenciamos sugere que a posição de observação de cada potencial licitante (no espaço onde decorre o leilão) assume capital importância.

O espaço onde se podem instalar os licitantes no caso da lota de Matosinhos tem o formato de uma bancada com quatro filas de cadeiras, dispostas em desnível. Se a observação dos concorrentes não fosse relevante, seria de esperar que os licitantes se dispusessem na bancada sem qualquer ordem aparente. No entanto, não foi isso que observámos, conforme se pode constatar na figura 2.

Tem sido sublinhado em diversos estudos sociais que, ao contrário do postulado pelas teorias ortodoxas, as decisões dos agentes em contexto de mercado envolvem invariavelmente um juízo sobre o que fazer em relação ao que se sabe acerca da atuação dos restantes agentes (e.g., DiMaggio, 2002; Davis, 2006). A nossa 


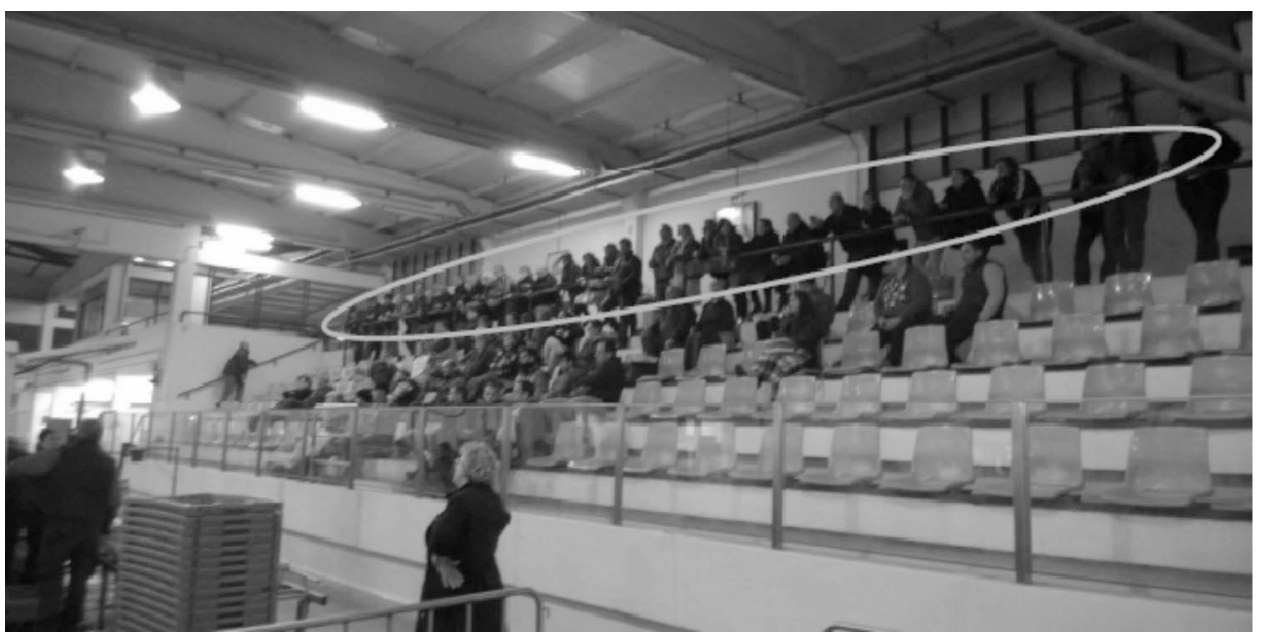

Figura 2 Posição escolhida pelos licitantes no leilão de pescado de Matosinhos (assinalada posição de licitantes localizados atrás da última fila de cadeiras)

Fonte: imagem captada pelo autor.

observação confirma essa asserção. Conforme se pode constatar na figura, cerca de $50 \%$ dos participantes nos leilões, de acordo com o que presenciámos na generalidade do período de observação, optam por ficar em pé, por detrás da última fila de cadeiras disponível. Apesar de ser mais desconfortável (alguns dos licitantes trazem cadeiras para se instalarem nessa posição), essa é considerada a melhor posição para observar os potenciais concorrentes no mercado. Tal sugere que os licitantes atribuem à sua localização uma importância estratégica (Cox, Robertson e Smith, 1982) e que a observação dos concorrentes é entendida como sendo um fator relevante. As condições de localização de cada participante face aos concorrentes, a sua localização no espaço do mercado conduz-nos necessariamente às condições materiais de realização do leilão.

\section{Complementando o social: a materialidade na construção do leilão de pescado}

No debate científico contemporâneo em matérias económicas é usual evidenciar-se a divisão entre dois mundos: um mundo das teorias altamente abstratas e assentes em pressupostos simplificadores e deliberadamente irrealistas, que tende a caracterizar a especulação de tipo neoclássico, e um mundo real, onde se valoriza a experiência histórica, a intuição prática e a análise comparada de eventos, típica de uma abordagem empírica do comportamento dito económico. Esta dicotomia, que é de certo modo reminiscente da metafísica de Platão - não por acaso, as teorias económicas neoclássicas têm sido caracterizadas como sendo neoplatónicas (McGoun e Zielonka, 2006) - 
não afasta a necessidade de se circular dos pressupostos e axiomas idealizados da teoria (neoclássica) para a materialidade do mundo físico.

Para aqueles que assumem uma oposição entre o mercado e as autoridades públicas, a criação do mercado de leilão por uma empresa detida a 100\% pelo estado português - a Docapesca é uma empresa integralmente pública - deve surgir como um paradoxo. No entanto, independentemente da natureza da entidade que institui esse mercado, a inserção do mercado - no nosso caso, um mercado de leilão de pescado - na materialidade do mundo real é inescapável.

A preocupação com a materialidade dos mercados, com a sua fisicalidade e com os seus aspetos técnicos, é uma das características mais marcantes dos estudos sociais em finanças e, em particular, da chamada "sociologia da materialidade" (MacKenzie, 2008). É que os indivíduos que constituem os mercados não são agentes desencarnados ou abstratos processadores de informação. Nem sequer são "apenas" seres humanos inseridos em instituições, convenções, relacionamentos pessoais e redes de socialização. São também seres humanos com um corpo; e os corpos são entidades físicas. Nesse sentido, os atores económicos, como defendem sociólogos como Michel Callon (2007), por exemplo, são constituídos por híbridos coletivos, ou seja, por combinações de seres humanos com objetos materiais e artefactos, sistemas técnicos, algoritmos. As capacidades e limitações dessas entidades materiais são então essenciais para se entender como os mercados são construídos.

É necessário perceber que os preços no mundo real são, também eles, uma entidade física - quer tomem a forma de ondas sonoras, quando são enunciados pelo leiloeiro ou transmitidos por telefone, quer quando são escritos, quer ainda quando assumem a forma de impulsos elétricos representando números binários, no caso de serem comunicados através de sistemas informáticos. Os preços têm que ser transmitidos de alguma forma entre os indivíduos ou entre sistemas informáticos e, em qualquer dos casos, a forma física que tomam (a sua materialidade) tem consequências relevantes para os envolvidos.

Mas então, como se produzem esses factos a que chamamos preços e que são comummente aceites por todos os presentes? Quais os componentes técnicos envolvidos na sua "fabricação"?

Um aspeto central na fabricação dos preços nos leilões da Docapesca, ou seja, na construção da sua materialidade, passa pela sua publicitação constante entre todos os participantes através de ecrãs informativos. Estes elementos de difusão de informação contêm, para além do preço propriamente dito, outros elementos, como o código identificativo do comprador, o preço do vendedor e códigos relativos à frescura do pescado. Os ecrãs observados no leilão de pescado surgem representados na figura 3 e na figura 4.

Conforme se pode observar na figura 3, existem no leilão de Matosinhos dois ecrãs que funcionam em simultâneo (com os preços a diminuir até ao surgimento da licitação vencedora) e que garantem que o pescado seja vendido mais rapidamente. A escolha de ter dois ecrãs a operar em simultâneo não é inédita - o mesmo ocorre no leilão holandês do Sydney Fish Market australiano, por exemplo - e tem implicações que extravasam o domínio económico. A existência, na prática, de dois leilões a funcionar ao mesmo tempo e no mesmo espaço, se cria um maior dinamismo à 


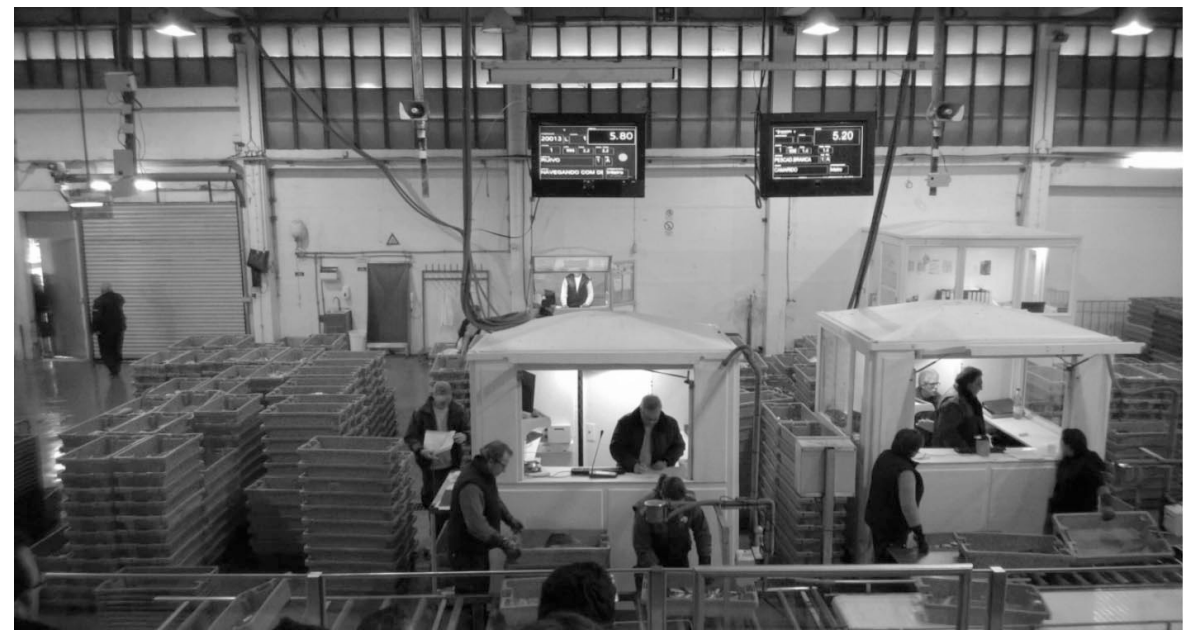

Figura 3 Ecrãs de divulgação dos resultados do leilão de cada lote de pescado (perspetiva desde o espaço atribuído aos licitadores)

Fonte: imagem captada pelo autor.

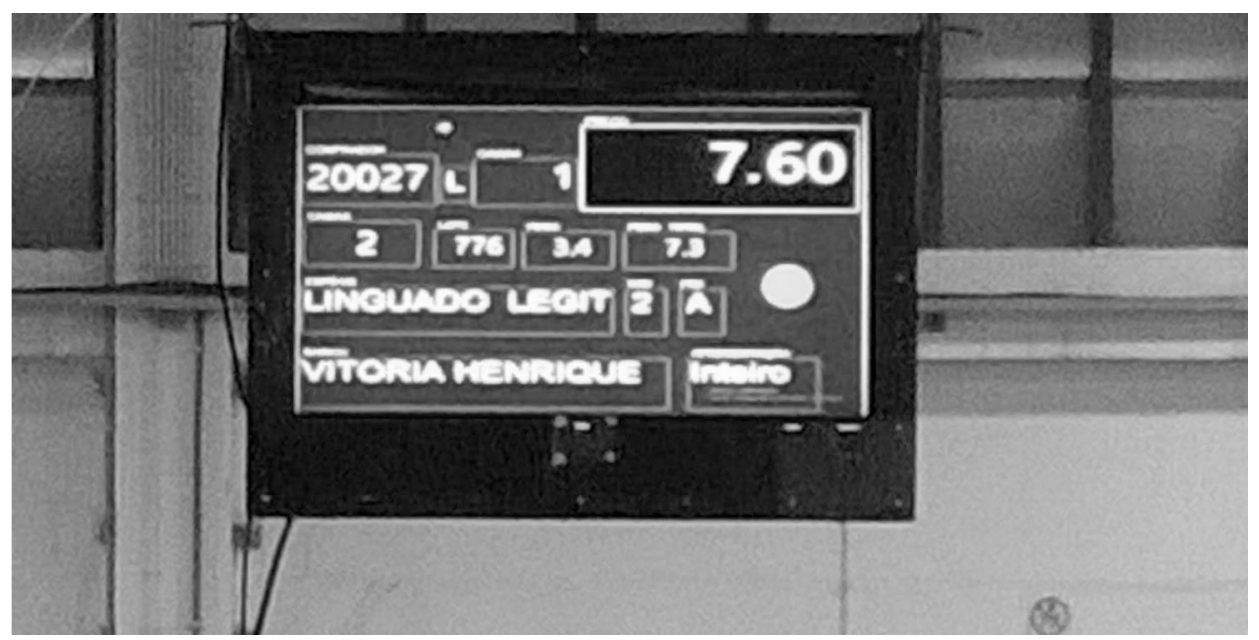

Figura 4 Ecrã de divulgação dos resultados do leilão de cada lote de pescado (perspetiva aproximada) Fonte: imagem captada pelo autor. 
negociação, também evidencia as limitações cognitivas dos agentes no seguimento dos negócios ativos a cada momento e, por esta via, tem o potencial para criar uma maior excitação emocional e competição social nos participantes. É que, conforme salienta Stark (2011), quanto maior é o volume de informação que está instantaneamente ao dispor de cada um dos agentes de mercado, mais as vantagens estratégicas transitam da economia da informação (que informação é que se tem) para o processo sociocognitivo de interpretação (como se interpreta a informação que se tem).

Se os seres humanos tivessem uma capacidade de cálculo, de memória e de processamento de informação ilimitada, um único indivíduo poderia em teoria atribuir um preço adequado a partir da transformação de toda a informação surgida nos ecrãs a cada momento. Ora, como os seres humanos têm limitações em termos cognitivos (Simon, 1955), é necessário atender à forma como as suas decisões se inserem no contexto dessas limitações. O papel da "inserção cognitiva" dos agentes sociais na construção dos mercados e a consequente necessidade de retratar a ação dos indivíduos atendendo à contingência da sua subordinação ao cognitivo é, por isso, um fator incontornável no estudo social das instituições económicas em geral (e.g. Zukin e DiMaggio, 1990; DiMaggio, 1997) e dos mercados de leilão em particular (e.g. Bagozzi, Baumgartner e Pieters, 1998).

A informação constante dos ecrãs, ao ser vista em simultâneo por todos os participantes do leilão, é igualmente um elemento essencial para se criar o sentido de comunidade a que nos referimos anteriormente. Mas o seu papel vai para além disso: os ecrãs, com as informações neles constantes, suprem as limitações de perceção dos licitadores. Mesmo os licitadores que se encontram mais afastados do leiloeiro (como os muitos que escolhem situar-se atrás da última fila de cadeiras, conforme mencionado acima), podem acompanhar a criação dos preços. Daqui se infere que os equipamentos que constituem os mercados produzem consequências ao condicionarem a natureza dos agentes económicos e a forma como estes atuam. No caso, é a tecnicidade do leilão de pescado (mais propriamente, a tecnicidade proporcionada pelos ecrãs) que permite aos participantes escolherem a sua localização no espaço físico, escolha essa que lhes permite, desse modo, atribuir importância estratégica à observação dos concorrentes e que fomenta o desenvolvimento do sentimento de comunidade que encontramos. As condições da materialidade reforçam a observação recíproca dos participantes.

Mas a interação entre a materialidade dos mercados e a sua constituição reflete-se também noutros domínios. Um aspeto relevante a ter em conta decorre das possibilidades conferidas pelo artefacto que permite que as licitações sejam comunicadas pelos licitantes ao leiloeiro: um comando que cada um dos licitantes possui e que surge representado na figura 5 .

Este comando é de dimensão suficientemente reduzida para dificultar a observação, prévia à publicitação da licitação, do interesse num determinado lote de pescado. Assim, se é verdade que a materialidade do mercado - com a simbiose entre aspetos humanos e tecnológicos que temos vindo a referir - permite o exercício de avaliações estratégicas na recolha de informação a partir dos pares, não é menos notório que é essa mesma tecnicidade (se bem que manifestada num outro 


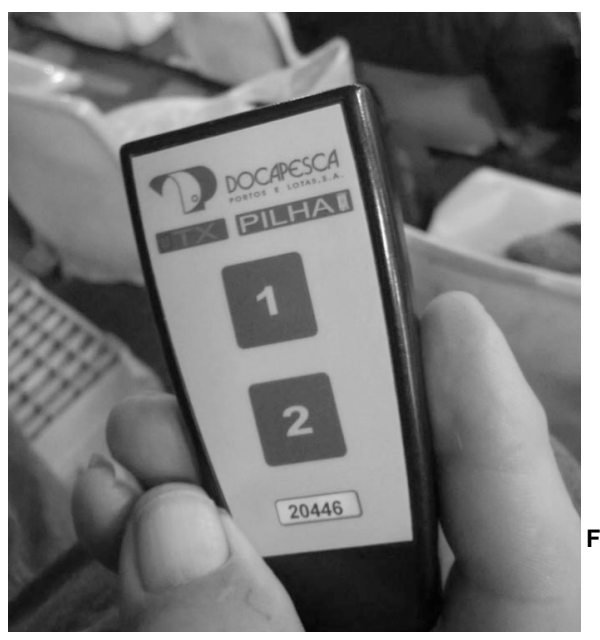

Figura 5 Comando de transmissão das licitações ao leiloeiro

Fonte: imagem captada pelo autor.

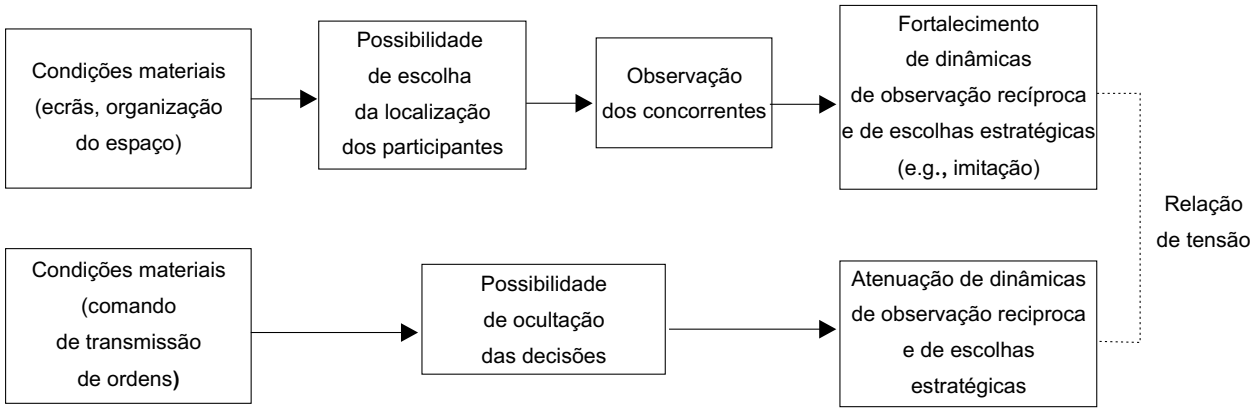

Figura 6 Relação de tensão entre condições de materialidade do mercado e exposição/ocultação das decisões dos participantes

artefacto) que permite responder à necessidade de manutenção da discrição antes da enunciação da licitação vencedora.

Deste modo, a relação de tensão entre as condições de materialidade e as dinâmicas de exposição/ocultação das decisões pode ser representada na figura 6 .

\section{Conclusão}

A nossa discussão, levada a cabo a partir da observação etnográfica do mercado da Docapesca, conduz-nos à asserção de que os preços são o resultado das condicionantes psicológicas, sociais e materiais que entram em jogo no contexto específico 
em que as trocas têm lugar. Nesta medida, os preços são o produto de um processo de "fabricação" (Muniesa, 2015; Boldyrev e Svetlova, 2016). A formação de preços não é algo que ocorra de forma espontânea no mundo natural e os mercados, como qualquer instituição económica, são artificiais por definição. Assim, é necessário atender aos ingredientes que estão presentes na fabricação dos preços. Por um lado, é necessário considerar que a construção de um mercado parte de um esforço deliberado por parte dos seus criadores (e.g., Garcia-Parpet, 2007). É útil, portanto, tentar perceber que motivações estão inscritas nas intenções conducentes ao ato fundador. Por outro lado, um entendimento apropriado dos mercados requer que se tenha em consideração tanto os aspetos físicos da sua organização como os aspetos psicossociais dos agentes que neles participam. Estes dois elementos, conforme vimos, estão intimamente ligados a ponto de serem difíceis de separar; existem associações não apenas entre os indivíduos (o aspeto social), mas também entre os indivíduos e os elementos não humanos (a materialidade dos mercados). A criação dos preços é por isso um processo coletivo, com facetas de colaboração e de conflito, frequentemente em tensão, e que envolve, em simultâneo, componentes físicas e psicossociais (Beunza, Hardie e MacKenzie, 2006; MacKenzie, 2006).

\section{Referências bibliográficas}

Adam, Marc T. P., Ami Eidels, Ewa Lux, e Timm Teubner (2017), “Bidding behavior in Dutch auctions: insights from a structured literature review", International Journal of Electronic Commerce, 21 (3), pp. 363-397.

Bagozzi, Richard P., Hans Baumgartner, e Rik Pieters (1998), "Goal-directed emotions", Cognition and Emotion, 12 (1), pp. 1-26.

Bestor, Theodore (2004), Tsukiji. The Fish Market at the Center of the World, Berkeley, University of California Press.

Beunza, Daniel, Iain Hardie, e Donald MacKenzie (2006), "A price is a social thing: towards a material sociology of arbitrage", Organization Studies, 27 (5), pp. 721-745.

Boldyrev, Ivan, e Ekaterina Svetlova (orgs.) (2016), Enacting Dismal Science. New Perspectives on the Performativity of Economics, Londres, Palgrave Macmillan.

Callon, Michel (2007), "What does it mean to say that economics is performative?", em Donald MacKenzie, Fabian Muniesa e Lucia Siu, Do Economists Make Markets? On the Performativity of Economics, Princeton, Princeton University Press, pp. 311-357.

Carruthers, Bruce G., e Jeong-Chul Kim (2011), “The sociology of finance”, Annual Review of Sociology, 37, pp. 239-259.

Cox, James C., Bruce Robertson, e Vernon L. Smith (1982), “Theory and behavior of single object auctions", Research in Experimental Economics, 2, pp. 1-43.

Davis, Aeron (2006), "Media effects and the question of the rational audience: lessons from the financial markets", Media, Culture \& Society, 28 (4), pp. 603-625.

DiMaggio, Paul (1997), “Culture and cognition”, Annual Review of Sociology, 23, pp. 263-267.

DiMaggio, Paul (2002), “Endogenizing 'animal spirits': towards a sociology of collective response to uncertainty and risk", em Marshall Meyer, Maruo F. Guillen, Randall 
Collins e Paula England, The New Economic Sociology. Developments in an Emerging Field, Nova Iorque, Russell Sage, pp. 79-100.

Docapesca (1989), Regulamento Interno de Exploração de Lotas, disponível em:

http://www.docapesca.pt/pt/rede-lotas-e-postos-vendagem/item/lota-de-matosinho s.html?category_id=4

Docapesca (2018), Estatísticas Mensais, disponível em: http://www.docapesca.pt/index.php

Garcia-Parpet, Marie-France (2007), “The social construction of a perfect market: the strawberry auction at Fontaines-en-Sologne", em Donald MacKenzie, Fabian Muniesa e Lucia Siu, Do Economists Make Markets? On the Performativity of Economics, Princeton, Princeton University Press, pp. 20-53.

Giulioni, Gianfranco, e Edgardo Bucciarelli (2011), "Agent's behaviour in a sequential Dutch auction: evidence from the Pescara wholesale fish market", Applied Economic Letters, 18 (5), pp. 455-460.

Glancy, Maureen (1990), "Socially organized role-taking: becoming an auction player", Leisure Sciences, 12 (4), pp. 349-366.

Godechot, Olivier (2001), Les Traders. Essai de Sociologie des Marchés Financiers, Paris, La Decouverte.

Hariharan, Anuja, Marc Thomas Philip Adam, Timm Teubner, e Christof Weinhardt (2015), "Think, feel, bid: the impact of environmental conditions on the role of bidders' cognitive and affective processes in auction bidding", Electronic Markets, 26 (4), pp. 1-17.

Ho, Karen (2009), Liquidated. An Ethnography of Wall Street, Durham, Duke University Press.

Katok, Elena, e Anthony M. Kwasnica (2008), “Time is money: the effect of clock speed on seller's revenue in Dutch auctions", Experimental Economics, 11 (4), pp. 344-357.

Knorr Cetina, Karin, e Urs Bruegger (2002), “Global microstructures: the virtual societies of financial markets", American Journal of Sociology, 107 (4), pp. 905-950.

Lépinay, Vincent Antonin (2011), Codes of Finance. Engineering Derivatives in a Global Bank, Princeton, Princeton University Press.

Lucking-Reiley, David (1999), “Using field experiments to test equivalence between auction formats: magic on the Internet", American Economic Review, 89 (5), pp. 1063-1079.

MacKenzie, Donald (2006), An Engine, Not a Camera. How Financial Models Shape Markets, Cambridge, CA, The MIT Press.

MacKenzie, Donald (2008), Material Markets. How Economic Agents Are Constructed, Oxford, Oxford University Press.

Mirowski, Philip, e Edward Nik-Khab (2007), "Markets made flesh: performativity, and a problem in Science Studies, augmented with consideration of the FCC Auctions", em Donald MacKenzie, Fabian Muniesa e Lucia Siu, Do Economists Make Markets? On the Performativity of Economics, Princeton, Princeton University Press, pp. 190-225.

McGoun, Elton G., e Piotr Zielonka (2006), “The Platonic foundations of finance and the interpretation of finance models", Journal of Behavioral Finance, 7 (1), pp. 43-57.

Muniesa, Fabian (2015), The Provoked Economy. Economic Reality and the Performative Turn, Nova Iorque, Routledge.

Público (2018), "Pescadores da sardinha fecham lota em protesto contra 'excesso de zelo' nas fiscalização", jornal Público (versão online), reportagem de André Vieira, disponível em: https://www.publico.pt/2018/06/13/economia/noticia/ 
protesto-de-pescadores-encerrou-lota-de-matosinhos-ao-inicio-da-manha-1834216

Rafaeli, Sheizaf, e Avi Noy (2005), “Social presence: influence on bidders in Internet auctions", Electronic Markets, 15 (2), pp. 158-175.

Simon, Herbert A. (1955), "A behavioral model of rational choice", Quarterly Journal of Economics, 69 (1), pp. 99-118.

Smith, Charles W. (1989), "Auctions: the social construction of value", em Charles W. Smith, Auctions. The Social Construction of Value, Nova Iorque, Free Press, pp. 112-132.

Smith, Kip, e John Dickhaut (2005), "Economics and emotion: institutions matter", Games and Economic Behavior, 52 (2), pp. 316-335.

Stark, David (2011), The Sense of Dissonance. Accounts of Worth in Economic Life, Princeton, Princeton University Press.

Zaloom, Caitlin (2006), Out of the Pits. Traders and Technology from Chicago to London, Chicago, The University of Chicago Press.

Zukin, Sharon, e Paul DiMaggio (1990), "Introduction", em Sharon Zukin e Paul DiMaggio, Structures of Capital. The Social Organization of the Economy, Cambridge, UK, Cambridge University Press, pp. 1-36.

Júlio Lobão. Professor auxiliar, Faculdade de Economia da Universidade do Porto, Rua Dr. Roberto Frias, 4200-464 Porto, Portugal. E-mail: jlobao@fep.up.pt

Receção: 04 de setembro de 2018 Aprovação: 24 de maio de 2019 